\title{
Phosphorus and Groundwater: Establishing Links Between Agricultural Use and Transport to Streams
}

\author{
Why Study Phosphorus?
}

Phosphorus is a highly reactive element that is essential for life and forms a variety of compounds in terrestrial and aquatic ecosystems. In water, phosphorus may be present as the orthophosphate ion $\left(\mathrm{PO}_{4}{ }^{3-}\right)$ and is also present in all life forms as an essential component of cellular material. In natural ecosystems, phosphorus is derived from the erosion of rocks and is conserved for plant growth as it is returned to the soil through animal waste and the decomposition of plant and animal tissue; but in agricultural systems, a portion of the phosphorus is removed with each harvest, especially since phosphorus is concentrated in the seeds and fruit. Phosphorus is added to soil by using chemical fertilizers, manure, and composted materials. Agricultural use of chemical phosphorus fertilizer, in the United States, in 2008 was 4,247,000 tons, which is an increase of 25 percent since 1964 (http://www.ers.usda.gov/Data/FertilizerUse/). Widely grown corn, soybeans, and wheat use the greatest amount of phosphorus fertilizer among agricultural crops.

Phosphorus is largely retained in soil by a process called adsorption. Soils have a limited capacity to store phosphorus, and once the capacity of soil to adsorb phosphorus is exceeded, the excess will dissolve and move more freely with water either directly to a stream or downward to an aquifer. Surface-water runoff from rainstorms or excess irrigation is the primary way that phosphorus or soil containing phosphorus is transported to streams in most watersheds. There is a growing awareness that long-term over-application of manure and chemical fertilizer contributes to phosphorus movement into the groundwater system, resulting in a significant groundwater source of phosphorus to streams and lakes, as well as potential contamination of the groundwater resources.

Leaching of applied fertilizer and surface runoff of phosphorus from the soil can contribute to excess growth of algae in downstream water bodies, a condition known as eutrophication. Excessive amounts of algae in eutrophic water bodies can cause large daily changes in the amount of dissolved oxygen in the water because oxygen concentrations tend to be high during daylight hours as a result of photosynthetic activity but then decrease at night. Low concentrations of dissolved oxygen can stress or kill sensitive species living in the water.

This study examined concentrations and movement of phosphorus in the soils and groundwater in five agricultural settings across the United States characterized by differences in soil geochemistry, climate, irrigation usage, and cropping systems to assess potential phosphorus movement in the soil and groundwater under common agricultural conditions. The study design included assessment of a variety of agricultural practices, especially cropping patterns and irrigation, so that the factors that contribute to phosphorus movement to groundwater, or sequestration of the phosphorus to soil could be compared and examined. This type of information could potentially be used to formulate best management practices to limit the transport of phosphorus from the agricultural fields.

\section{Study Design and Locations}

The study was conducted at five study areas across the country (fig. 1). Study sites in Washington (DR2 Drain) and California (Lower Merced River) are representative of agriculture in arid regions of the western United States, where all agriculture requires irrigation. Agriculture at these two sites includes orchards, fruits, and row crops. Large dairy operations also are present. Sites in Nebraska (Maple Creek), Indiana (Leary Weber Ditch), and Maryland (Morgan Creek) represent typical corn-soybean agriculture in three soil and rainfall conditions. Corn and soybean fields are typically rotated, but recently corn for fuel has replaced soybeans in some areas. The Nebraska site has welldrained soils in the sub-humid central U. S., where irrigation sometimes is used to supplement rainfall to meet crop water demands. The Indiana site is representative of poorly drained soils in the humid Midwestern U.S. that are drained by tile drains (systems of buried permeable pipe). The Maryland site has well-drained soils common to the humid Atlantic Coastal Plain. The Indiana and Maryland sites are not irrigated as rainfall is usually adequate to supply the water needs of crops.

At each site, samples of water and sediment from the unsaturated zone (the region below land surface but above the aquifer that is not completely saturated with water), the aquifer, the stream, and the

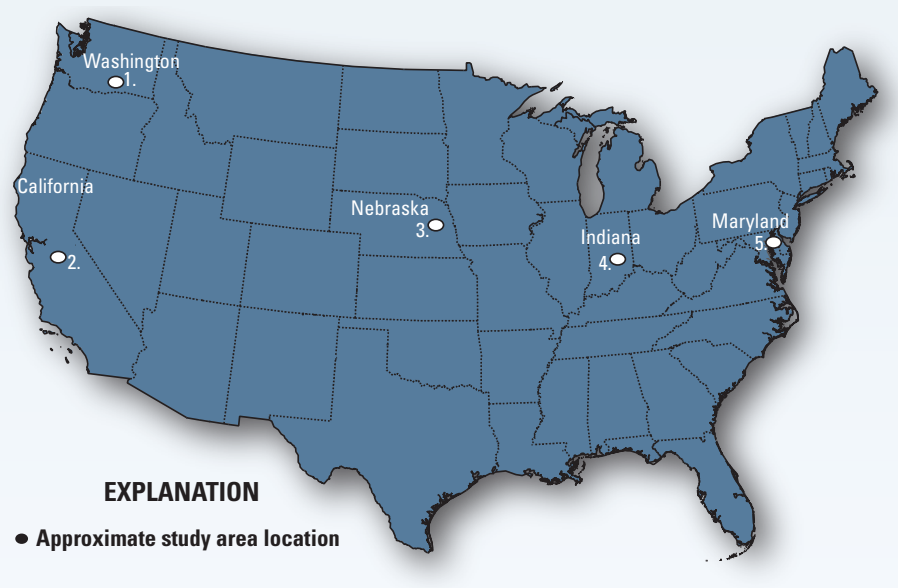

Figure 1. Research was conducted in five study areas: (1) DR2 Drain; (2) Lower Merced River; (3) Maple Creek; (4) Leary Weber Ditch; and (5) Morgan Creek, Maryland. 
interface of the groundwater and the stream (just below the streambed) were analyzed for phosphorus, major ions, and sediment properties that contribute to adsorption. At the Indiana location, tile drains also were sampled and analyzed by using the same methods as for the other water samples. In addition to chemical analyses, measurements of soil water content and groundwater levels were continuously recorded in order to determine the rate of downward water movement in the unsaturated zone and the general direction of groundwater flow. Wells were also installed in the streambed sediments in order to determine the movement of water and chemicals across this interface between the river and groundwater. Dissolved phosphorus can move vertically across the streambed interface in either direction, and that process can alter the phosphorus concentration in streams and groundwater (fig. 2).

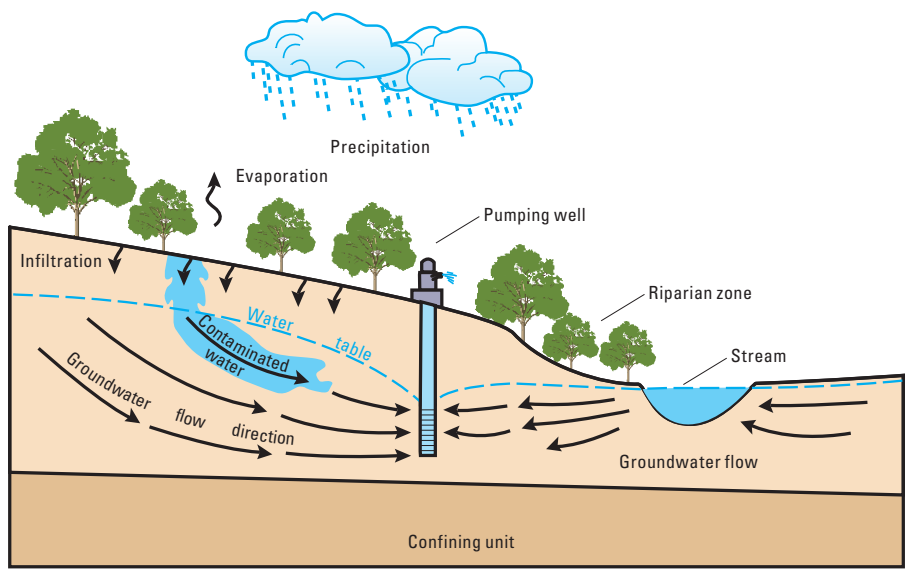

Figure 2. Schematic of a groundwater-flow system in an agricultural setting. In this example, infiltration of water from either precipitation or irrigation can transport phosphorus or other chemicals to the unsaturated zone and aquifer.

\section{Concentrations of Phosphorus Exceed US EPA Criteria at Some Sites}

Concentrations of dissolved phosphorus (fig. 3) at some of the streams were above the recommended regional criteria for total phosphorus established by the U.S. Environmental Protection Agency (USEPA) for the protection of streams in these regions (http://www. epa.gov/waterscience/criteria/nutrient/ecoregions/). The criteria differ among the sites because of natural variations in background concentrations across the country. The USEPA criteria are for total phosphorus, but our study was for dissolved phosphorus only. Total phosphorus includes dissolved phosphorus plus the phosphorus found in particles or bound to sediment. Total phosphorus tends to have higher concentrations than dissolved phosphorus alone; however, in groundwater, dissolved phosphorus is usually the same as total phosphorus.

In Washington and Nebraska, regional ecosystem nutrient criteria were exceeded in over 75 percent of the stream samples; however, this situation occurred much less frequently in stream samples from California, Indiana, and Maryland. At sites with high concentrations in groundwater, groundwater discharge can increase the concentrations in the streams. At the Nebraska site, median concentrations in groundwater and streambed water were similar to those observed in the stream, indicating that groundwater is a source of phosphorus. At the Washington and Maryland sites, phosphorus concentrations in the groundwater were lower than observed in the streams, indicating that groundwater discharge can serve to dilute (and lower) concentrations in the streams. At the California site, most phosphorus concentrations in the stream were below the criteria, despite higher concentrations observed in the groundwater. In Indiana, phosphorus concentrations were low in the unsaturated zone, tile drains, the stream and in the groundwater. Exten- sive networks of tile drains at the Indiana site intercept much of the infiltrating water that would otherwise reach the groundwater. The low concentrations in the unsaturated zone at the Indiana site indicate that phosphorus is adsorbed strongly by the soil. Variations in phosphorus concentrations among the hydrologic compartments at different sites indicate that several processes affect phosphorus concentrations and potential movement in the environment.

\section{Effects of Geochemical Conditions on Subsurface Orthophosphate Movement}

Chemical phosphorus fertilizer is applied to the soil in a soluble form, and dissolved phosphorus can leach from manure that is also applied as fertilizer. Adsorption and mineralization can immobilize phosphorus and limit its movement within or below the root zone. In water, inorganic phosphorus primarily occurs as orthophosphate, which carries a negative charge. Although orthophosphate is soluble in water, it can bind or adsorb onto soil particles. The two types of minerals primarily responsible for orthophosphate adsorption in soils are clays and metal oxides, with fine-grained iron oxides responsible for most orthophosphate adsorption in the soil subsurface. Additionally, soils rich in calcium carbonate can limit phosphorus movement as a result of the formation of calcium phosphate minerals. The amount of orthophosphate that can be adsorbed is limited by the amount of total surface area of the oxides or clays in a soil. When the sorption sites on the mineral surfaces become saturated with orthophosphate or other ions, any additional orthophosphate will remain in solution. When a soil nears or reaches saturation, dissolved phosphorus can be transported to deeper portions of the unsaturated zone and into the underlying aquifer as soil water moves downward.

The ability of iron oxides to adsorb and retain orthophosphate depends upon the presence of dissolved oxygen in the surrounding water and below-neutral $\mathrm{pH}$ (less than 7). In general, soils and aquifers lacking dissolved oxygen or having $\mathrm{pH}$ values greater than about 7 will tend to become saturated with orthophosphate more quickly than oxic

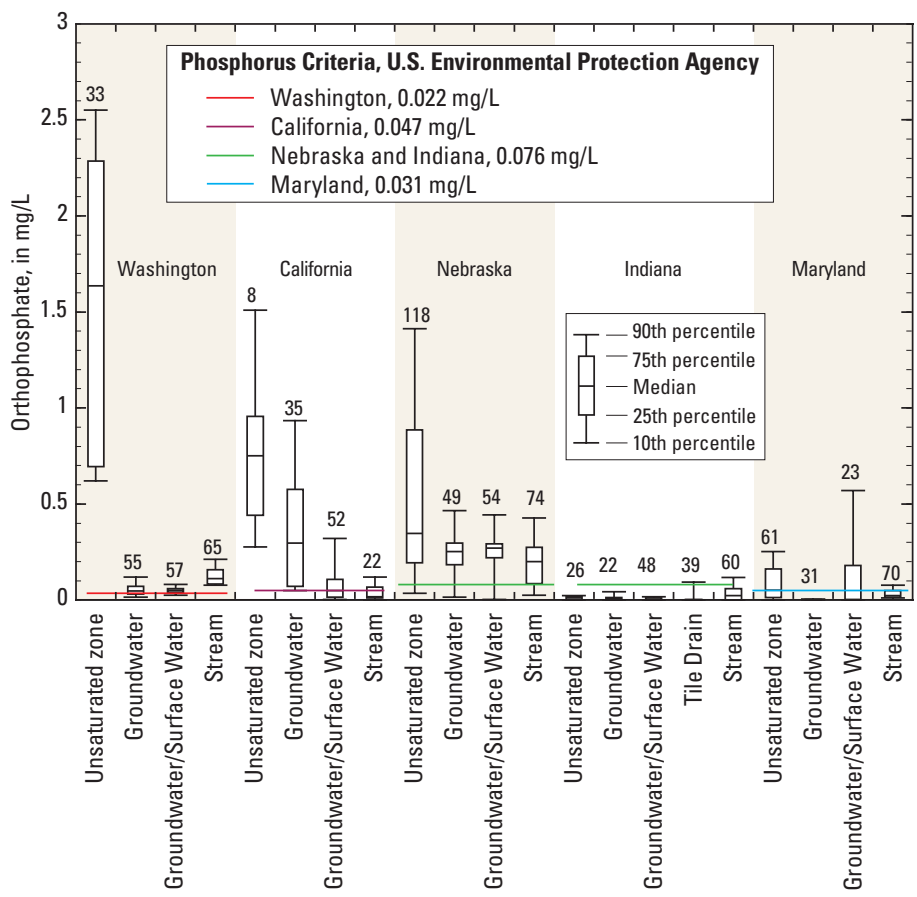

Figure 3. Concentrations of dissolved phosphorus $(\mathrm{P})$, in milligrams per liter $(\mathrm{mg} / \mathrm{L})$ as $P$, in different hydrologic compartments at each study area relative to USEPA recommended total phosphorus criteria for each region. Numbers above each plot refer to the total number of samples analyzed. 
or acidic soils and aquifers. In the absence of oxygen, iron oxides can dissolve and release adsorbed phosphorus back into the water, where concentrations of dissolved phosphorus increase. Even in an aquifer that has low amounts of dissolved oxygen, however, iron oxides do not necessarily dissolve, because this process is related to the presence of specific bacteria.

Phosphorus in sediment in the unsaturated zones and aquifers

Soil analyses are available to measure the portion of soil phosphorus that can be utilized by plants or become mobilized to soil water. This phosphorus can be referred to as "environmentally available.” These measurements are useful for agriculturalists to determine the specific crop needs for phosphorus, and the concentrations of phosphorus measured by these tests also can be used as a surrogate for the amount of phosphorus adsorbed to the soil. Sediment samples collected from the unsaturated zone, the aquifers, and the streambed (groundwater/stream-water interface) were analyzed for this form of phosphorus.

Environmentally available phosphorus concentrations varied across the five study sites. The distribution of environmentally available phosphorus at three study sites shown in figure 4 are examples of this. The highest concentrations of phosphorus are found near the land surface because of fertilizer application. Concentrations decrease with depth at all locations. Higher concentrations of soil-bound phosphorus near the surface indicate that saturation could occur and that further applications of phosphorus could result in subsequent downward movement of phosphorus to deeper horizons.

\section{Influence of iron-oxide minerals and $\mathrm{pH}$ on} phosphorus movement

The presence of dissolved oxygen in the unsaturated zone at all sites ensured that iron oxides were stable in that hydrologic environment. At four of the five sites, iron

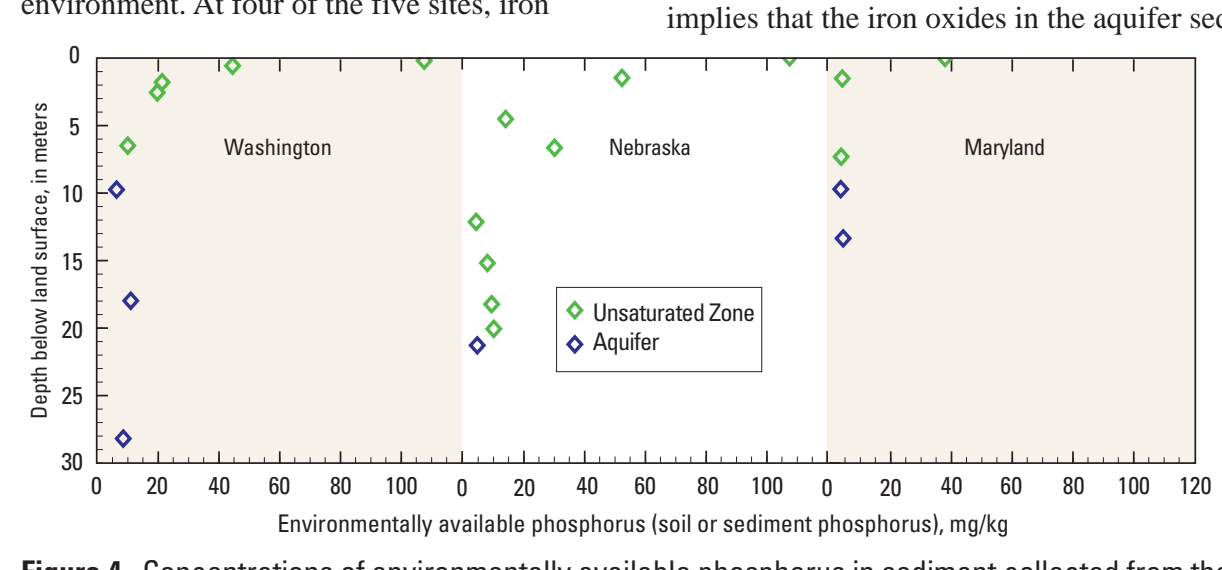

Figure 4. Concentrations of environmentally available phosphorus in sediment collected from the oxides were assumed to be the most important control on the levels of orthophosphate dissolved in water. However, it was not possible to determine the mechanism of phosphorus control at the Indiana site. Phosphorus concentrations were low in all hydrologic compartments, suggesting that phosphorus was effectively sequestered and immobile. It was unclear as to whether adsorption onto oxides was the primary controlling factor, or some other process. Other possible processes include precipitation of a phosphorus mineral or co-precipitation of phosphorus with a mineral such as calcium carbonate. In the aquifers underlying the five study sites, iron oxides were found in varying quantities. Relatively higher amounts were found at the Washingat the Nebraska location (fig. 5). The small amounts of iron oxide present in the Nebraska aquifer sediments partially were attributed to low dissolved oxygen concentrations present throughout the aquifer.

The $\mathrm{pH}$ of the unsaturated-zone and aquifer water was close to neutral or slightly alkaline at four of the study locations (fig. 5). At the Maryland site, the unsaturated-zone water was close to a neutral $\mathrm{pH}$, but the groundwater was slightly acidic. Analysis of these $\mathrm{pH}$ data implies that the iron oxides in the aquifer sediton location and relatively lower amounts unsaturated zone and aquifers at the Washington, Nebraska, and Maryland study sites.

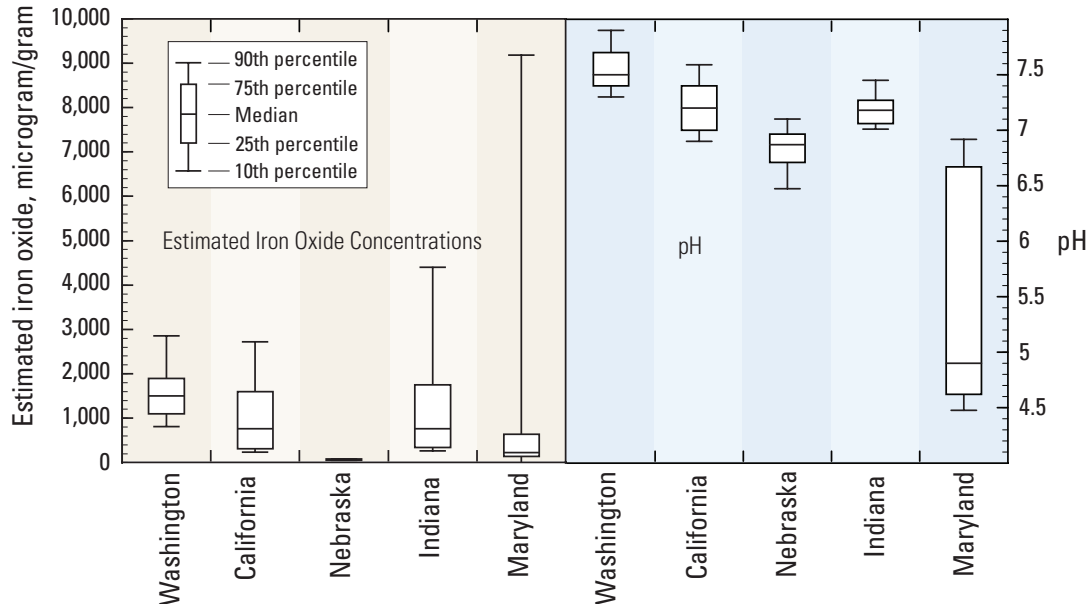

Figure 5. Concentrations of iron oxide in aquifer sediment, and $\mathrm{pH}$ for both the unsaturated-zone water and groundwater, respectively, at the five study sites.

ments at Maryland have the greatest capacity to adsorb and retain orthophosphate compared with aquifer sediments at the other four sites.

\section{Modeling Phosphorus Saturation and Move- ment}

A geochemical model was used to calculate the amount of phosphorus adsorbed onto the available iron-oxide surfaces in the unsaturated zones and aquifers. The amount of phosphorus that aquifer sediments can adsorb is related to the amount of iron oxides present, the $\mathrm{pH}$, the total amount of phosphorus present, the amount of dissolved oxygen in water, and other ions in solution. When phosphorus concentrations in an aquifer are low, the oxide surfaces probably are undersaturated and can adsorb more. Higher concentrations of phosphorus in groundwater indicate that the oxide surfaces are saturated or becoming saturated. A comparison of adsorption at two sites (Maryland and Nebraska) is shown in figure 6. The Maryland aquifer has more iron oxide compared to the one in Nebraska, and the groundwater has a lower $\mathrm{pH}$. As a result, the oxides in the Maryland example are undersaturated, and phosphorus levels in groundwater are barely detectable. In contrast, the oxide surfaces are more highly saturated at the Nebraska location, and as a result, the concentrations of orthophosphate in the groundwater are much higher than those observed at the Maryland site.

Transport of dissolved orthophosphate below the unsaturated zone to the aquifer can be demonstrated with the California site. A cross section of the groundwater system is shown in figure 7. Concentrations of dissolved phosphorus in the unsaturated zone at the California site (fig. 3) are above the USEPA criteria for protection of streams, and these concentrations occur because iron oxides are near saturation with respect to orthophosphate. Below the orchards and the 


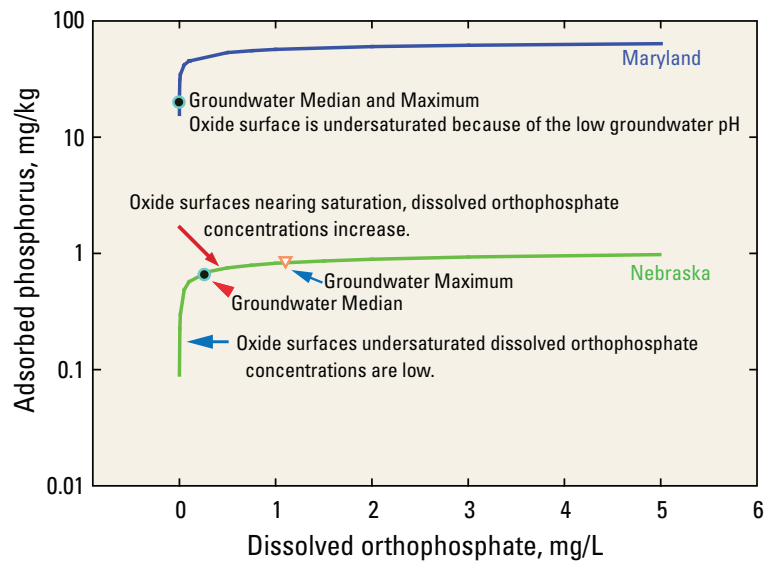

Figure 6. Sorption plots with maximum and median concentrations of dissolved phosphorus in groundwater, for the Maryland and Nebraska study sites. Oxides are considered to be unsaturated where the isotherms are more vertical, but saturated where the isotherms become more horizontal.

cornfield, the aquifer oxides are also near saturation (as indicated by modeling and measurement of phosphorus in the aquifer sediment), and as a result, dissolved orthophosphate also is elevated relative to the USEPA criteria for stream protection. In the riparian zone downgradient of the corn field (figure 7), concentrations of dissolved phosphorus are lower than those observed beneath the orchards; this occurs because the iron oxides in the riparian zone are undersaturated, as indicated by the modeling, and can absorb additional phosphorus. The riparian zone, composed of natural vegetation and not fertilized, limits the transport of orthophosphate in groundwater to the stream. As a result, concentrations of orthophosphate below the Merced River streambed (groundwater/ stream-water interface) are typically less than the USEPA suggested criteria at this location. The concentration of orthophosphate increases below the confining layer because of the lack of dissolved oxygen which results in the dissolution of iron oxide minerals.

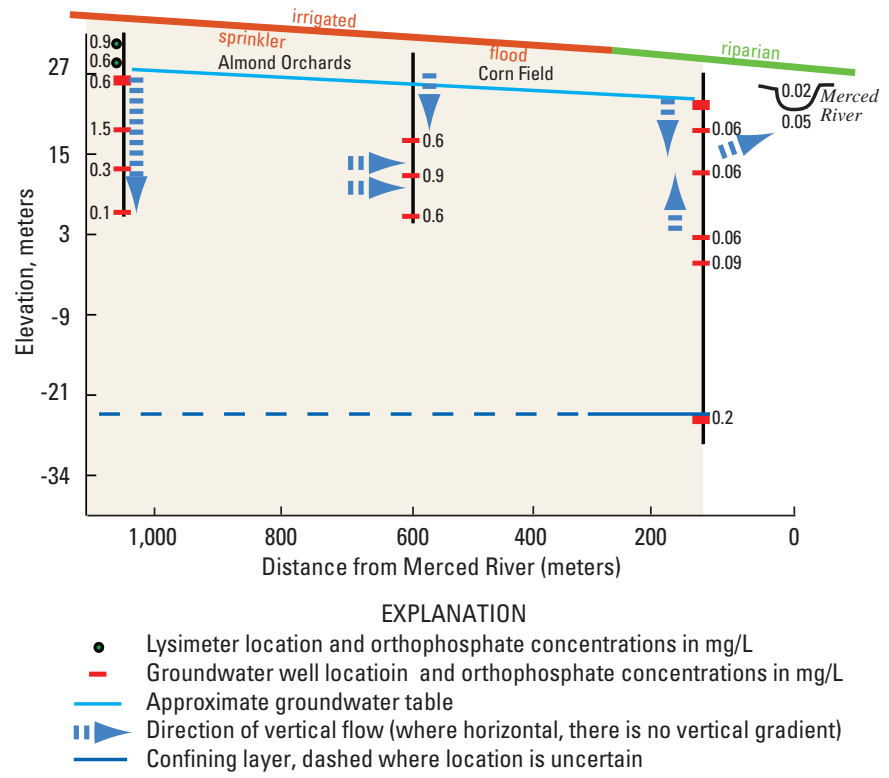

Figure 7. Cross-section of California flow system below orchards, corn field, and riparian zone. Concentrations of dissolved phosphorus, in $\mathrm{mg} / \mathrm{L}$, are shown for different parts of the flow system, including the groundwater/surface water interface (streambed) and river.

\section{Implication for Management}

The results of this study demonstrate that saturation of the soil or groundwater system with respect to phosphorus is possible and should be taken into account to protect downstream water bodies from excess phosphorus. Inexpensive soil tests that are routinely employed to estimate fertilizer requirements can be used on deeper soil samples to evaluate the potential for downward movement of phosphorus below the plant rooting depth in agricultural areas. The potential for groundwater transport of phosphorus can be evaluated with basic geochemical information, such as measurements of $\mathrm{pH}$, dissolved oxygen, and dissolved phosphorus in samples of shallow ground water. In some cases, a simple management practice, such as the maintenance of a buffer strip adjacent to a stream can be effective in limiting the groundwater transport of phosphorus to the stream. In order for a buffer strip to be effective, however, it must be shown that the aquifer underlying the riparian zone is capable of adsorbing enough phosphorus to lower the groundwater concentrations. Low concentrations of iron oxides or low dissolved oxygen in the aquifer underlying the buffer strip would substantially reduce its effectiveness. Further research on the effectiveness of buffer strips for phosphorus management in a variety of agricultural settings is warranted.

\section{NAWOA Agricultural Chemicals Transport Study}

The study of agricultural chemicals is one of several priority topics currently being addressed by the National Water-Quality Assessment (NAWQA) Program during its second decade of studies, which began in 2001. Seven watersheds were selected in major agricultural regions with different climate and soil types (Capel et al., 2004, McCarthy and Capel, 2009, http://in.water.usgs.gov/NAWQA_ACT/). The goals included developing an understanding of how chemicals move through different parts of the hydrologic system and how these parts of the system are inter-connected, and comparing and contrasting these processes in different geographic regions. This Fact Sheet highlights findings from an examination of phosphorus occurrence and transport in groundwater of five of the seven agricultural watersheds that make up the Agricultural Chemicals Transport study (Domagalski and Johnson, 2010).

\section{References}

Capel, P. D., Hamilton, P. A., and Erwin, M. L. , 2004, Studies by the U. S. Geological Survey on sources, transport, and fate of agricultural chemicals: U. S. Geological Survey Fact Sheet 2004-3098, 4 p., available at http://pubs.usgs.gov/fs/2004/3098/.

Domagalski, J. L. , and Johnson, H. M. , 2011, Comparative Study of Phosphorus Transport in the Unsaturated Zone, Groundwater, Streams, and Tile Drains at Five Agricultural Watersheds, U. S. A.: Journal of Hydrology, v. 409, p.157-171.

McCarthy, K. , and Capel, P. , 2009, A Whole-System Approach to Understanding Agricultural Chemicals in the Environment: U. S. Geological Survey Fact Sheet 2009-3042, 6 p. , available at http:// pubs.usgs.gov/fs/2009/3042/.

\section{By Joseph L Domagalski* and Henry Johnson}

*U.S. Geological Survey, California Water Science Center, $6000 \mathrm{~J}$ Street, Placer Hall, Sacramento, CA 95819. 